\title{
Ten-year incidence of primary angle closure in elderly Chinese: the Liwan Eye Study
}

\author{
Lanhua Wang, ${ }^{1}$ Wenyong Huang, ${ }^{1}$ Shengsong Huang, ${ }^{1}$ Jian Zhang, ${ }^{1}$ Xinxing Guo, \\ David S Friedman, ${ }^{2}$ Paul J Foster, ${ }^{3}$ Mingguang He $\mathrm{He}^{1,4}$
}

\begin{abstract}
- Additional material is published online only. To view please visit the journal online (http://dx.doi.org/10.1136/ 10.1136/bjophthalmol-2017311808).
\end{abstract}

${ }^{1}$ State Key Laboratory of Ophthalmology, Zhongshan Ophthalmic Center, Sun Yat-sen University, Guangzhou, China ${ }^{2}$ Dana Center for Preventive Ophthalmology, Wilmer Eye Institute, Johns Hopkins University School of Medicine, Baltimore, Maryland, USA ${ }^{3} \mathrm{NIHR}$ Biomedical Research Centre at Moorfields Eye Hospital and UCL Institute of Ophthalmology, London, UK ${ }^{4}$ Centre for Eye Research Australia; Ophthalmology, Department of Surgery, University of Melbourne Melbourne, Australia

\section{Correspondence to} Professor Mingguang He, State Key Laboratory of Ophthalmology, Zhongshan Ophthalmic Center, Sun Yat-sen University, Guangzhou 510060, China; mingguanghe@gmail. com

Received 4 January 2018 Accepted 13 April 2018 Published Online First 18 May 2018

\begin{abstract}
Purpose To determine the 10-year incidence of all forms of primary angle closure (PAC) in phakic eyes and its risk factors in an urban Chinese population aged 50 years and older.

Methods Survivors of 1405 baseline participants were invited to attend the 10-year follow-up visit in the Liwan Eye Study. Participants with established baseline angle closure, including primary angle closure suspects (PACS), PAC and primary angle closure glaucoma (PACG), or those who underwent bilateral cataract surgery during the 10-year period, as well as those who did not tolerate gonioscopic examinations, were excluded from this analysis. Incident PAC was present when those with open angles at baseline developed angle closure in any form in either eye during the 10-year period.

Results Among 791 participants who returned during the 10-year follow-up visit, 620 (78.4\%) provided data on PAC incidence. The 10-year cumulative incidence of any forms of PAC was $20.5 \%(127 / 620,95 \% \mathrm{Cl}$ $17.4 \%$ to $24.9 \%$ ), including $16.9 \%, 2.4 \%$ and $1.1 \%$ with incident PACS, PAC and PACG in either eye, respectively. In multiple logistic regression, significant risk factors for incident angle closure were greater baseline lens thickness ( $O R=1.82$ per $\mathrm{mm}, \mathrm{p}=0.003)$, shallower anterior chamber depth $(\mathrm{OR}=3.18 \mathrm{per}$ $\mathrm{mm}$ decreased, $\mathrm{p}=0.010$ ) and narrower angle width $(O R=1.63$ per decreased angle width, $p<0.0001)$. Conclusions Approximately one in five people aged 50 years and older developed some form of angle closure over a 10-year period. Small ocular dimensions and hyperopia at baseline were associated with the development of angle closure.
\end{abstract}

\section{INTRODUCTION}

Primary angle closure (PAC) is an important eye health problem affecting an estimated 79.6 million people in 2020, of whom 5.3 million will be blind. The prevalence of PAC varies by race, with especially high rates among Chinese populations. It is estimated that China will be home to $48 \%$ of all PAC cases globally in 2020. ${ }^{1}$ The PAC spectrum is divided into primary angle closure suspects (PACS), PAC and primary angle closure glaucoma (PACG). ${ }^{2} 3$

Data on the incidence of PAC are scarce. A study of an Indian population aged 40 years and older found that the incidence of PAC was $4.0 \%$ after 6-year follow-up periods ( $0.7 \%$ annually). ${ }^{4}$ Among Inuit individuals with a shallow anterior chamber, 16\% developed PACG at a 10-year follow-up visit. ${ }^{5}$ A study of a Mongolian population aged 50 years and older found a PACS incidence of 20.4\% among participants with a central anterior chamber depth (ACD) of $<2.53 \mathrm{~mm}$ over a 6 -year follow-up period. $^{6}$ To date, there have been no population-based cohort studies of the incidence of PAC among Chinese people.

We have previously reported the prevalence of PACS, PAC and PACG in urban southern China. The aim of the current study is to determine the 10-year incidence of any forms of PAC in phakic eyes in this Chinese population and its associated predictors.

\section{METHODS}

\section{Study population}

The Liwan Eye Study was a population-based study initiated in 2003. A 10-year follow-up examination was conducted in 2013, following the same protocol. At baseline, $75.4 \%$ (1405 of 1864) of eligible subjects aged 50 years and older completed a comprehensive eye examination and a questionnaire interview regarding education, income, hypertension and diabetes mellitus. All participants in the baseline study were invited to take part in follow-up examinations 10 years later. This follow-up study included 791 participants $(73.8 \%$ of survivors, $86.2 \%$ of eligible subjects) who returned for the repeat examinations in 2013.

The study was conducted in accordance with the tenets of the World Medical Association's Declaration of Helsinki. Written informed consent was obtained from all participants.

Participants who were diagnosed with any form of PAC or primary open angle glaucoma (POAG) at baseline and those who had bilateral cataract surgery during the 10-year follow-up (if it was unilateral cataract surgery, untreated eyes were used for outcome analysis), as well as individuals who did not tolerate gonioscopic examinations, were excluded from the analysis.

\section{Study procedures}

Detailed information of the gonioscopic examination in the Liwan Eye Study has been described previously. ${ }^{7}$ Briefly, all participants underwent slit lamp examination (SL-8Z; Topcon, Tokyo, Japan; with a D1x digital image system; Nikon, Tokyo, Japan), and static and dynamic gonioscopy with a Goldmann-type, one-mirror lens (Haag-Streit, Bern, Switzerland) at $\times 25$ magnification by the same experienced ophthalmologist $(\mathrm{MH})$, whose observations were standardised against those of an experienced gonioscopist (PJF). ${ }^{7}$ A narrow beam of 
light $1 \mathrm{~mm}$ in length was used for static examinations. Care was taken to avoid the miotic effect of light on the pupil as well as inadvertent indentation. Dynamic examination with increased illumination was performed after static gonioscopy. The Shaffer system $^{8}$ was used to assess the degree of angle width in the superior and inferior quadrants and then was recorded using five categories $\left(0^{\circ}, 10^{\circ}, 20^{\circ}, 30^{\circ}\right.$ and $\left.>40^{\circ}\right)$. Iris insertion was recorded in five categories from A (anterior to Schwalbe's line) to $\mathrm{E}$ (with a very wide ciliary body band).

The definitions developed by the International Society of Geographical and Epidemiological Ophthalmology were used for various states of angle closure and are as follows ${ }^{2}$ : PACS: an eye with $270^{\circ}$ or more in which the posterior pigmented trabecular meshwork could not be seen during a static examination, with intraocular pressure (IOP) $<21 \mathrm{~mm} \mathrm{Hg}$ and no peripheral anterior synechiae (PAS), previous acute angle closure or glaucomatous optic neuropathy; and PAC/G: an eye with $270^{\circ}$ or more in which the posterior pigmented trabecular meshwork could not be seen, with established PAS and/or IOP > $21 \mathrm{~mm} \mathrm{Hg}$ and/ or glaucomatous optic neuropathy. Incident angle closure was defined as occurring in participants with baseline open angles who developed any form of PAC (PACS or PAC/G) in either phakic eye during the 10 -year follow-up period.

Non-cycloplegic refractions were obtained using a handheld autorefractor (ARK-30; Nidek, Gamagori, Japan) and spherical equivalent (SE) was calculated as sphere plus half of the cylinder. A-scan ultrasound (Echoscan US1800, Nidek) was used to measure axial length (AL), ACD, lens thickness (LT) and central cornea thickness before mydriasis. Absolute lens position (ALP) was defined as ACD $+1 / 2 \times \mathrm{LT}$ and relative lens position as ALP/AL. IOP was measured before mydriasis using a handheld tonometer (Tono-Pen; Mentor, Norwell, Massachusetts, USA). All participants underwent height and weight measurements.
Body mass index was calculated as weight in kilograms divided by the square of height in metres.

\section{Statistical analysis}

All statistical analyses were performed using Stata (V.10.0). The 10-year incidence of any form of angle closure by age and gender was calculated. Student's t-test was used to compare continuous variables, while Pearson's $\chi^{2}$ or Fisher's exact test was used for the comparison of categorical data. We used ocular factors of the right eye for cases where either both eyes and the right eye only developed PAC. For those with incident PAC only in the left eye, ocular factors of the left eye were used. Multivariate logistic regression models were used to identify the baseline risk factors for the occurrence of any angle closure. Receiver operating characteristic (ROC) curves and area under the curve (AUC) were used to test the performance of baseline ocular parameters in predicting the incidence of any forms of PAC. Statistical significance was defined as a $\mathrm{p}$ value of $<0.05$.

\section{RESULTS}

Of the 1405 participants in the baseline examination, 320 (22.8\%) were deceased and 167 (11.9\%) had relocated outside of the study area during the 10-year follow-up. Another 127 $(9.0 \%)$ refused to attend to the final visit, leaving 791 (72.9\% of the survivors) with a mean baseline age of $62.3 \pm 8.7$ years who completed the 10-year follow-up (figure 1). The 791 attendees tended to be younger, male and were more likely to have hypertension (online supplementary table 1 ).

Among the 791 participants who completed the 10-year follow-up examination, a total of $620(79.4 \%)$ with a mean age of $60.9 \pm 8.3$ years had sufficient data to determine the incidence of PAC (figure 1). The 171 (21.6\%) excluded participants included those with any forms of PAC $(69,40.4 \%)$ or POAG $(9$,

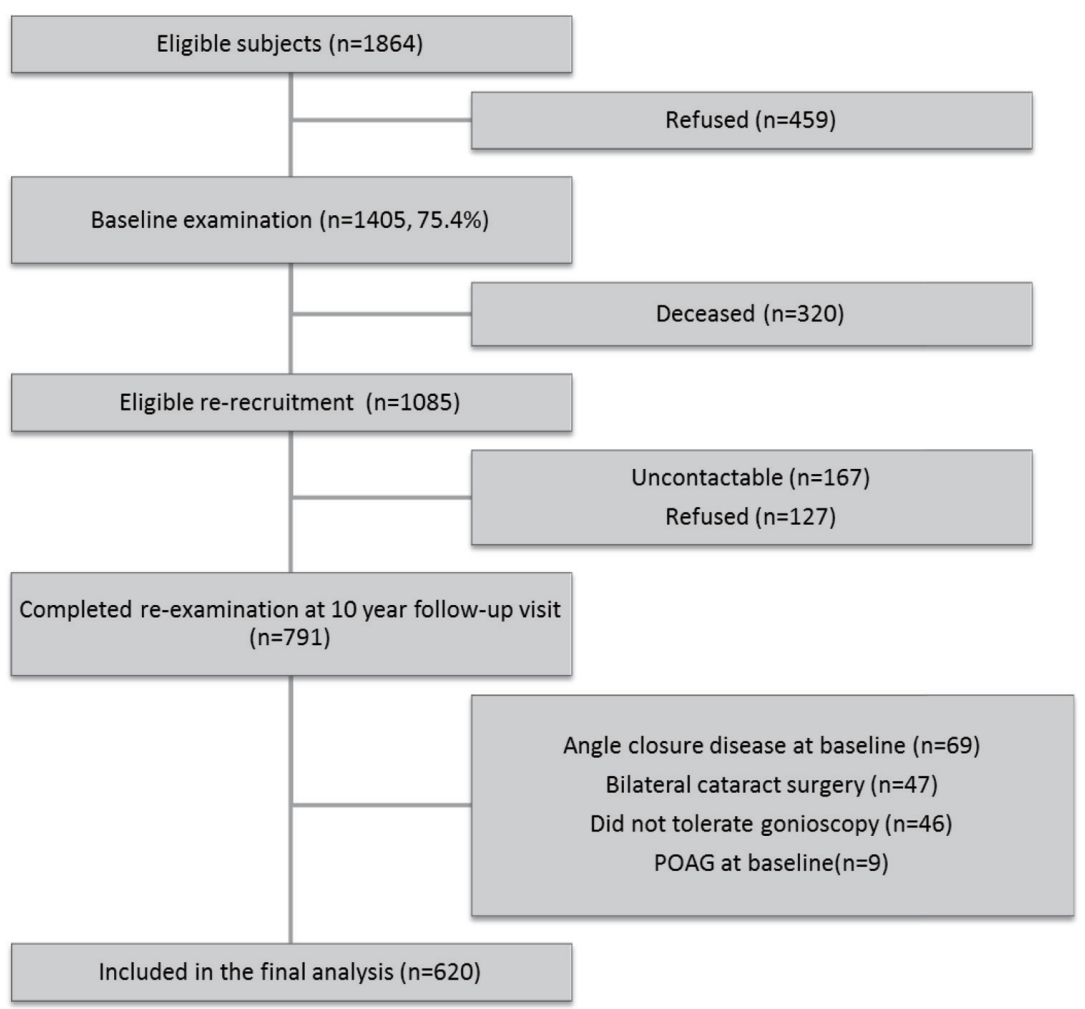

Figure 1 Flow chart showing the enrolment of participants in the Liwan Eye Study. POAG, primary open angle glaucoma. 
Table 1 Ten-year incidence of any forms of primary angle closure disease by age and gender in the Liwan Eye Study

\begin{tabular}{|c|c|c|c|c|c|c|}
\hline \multirow[b]{2}{*}{ Age at baseline (years) } & \multicolumn{2}{|l|}{ All } & \multicolumn{2}{|l|}{ Male } & \multicolumn{2}{|l|}{ Female } \\
\hline & $\mathrm{n} / \mathrm{N}$ & $\%(95 \% \mathrm{Cl})$ & $\mathrm{n} / \mathrm{N}$ & $\%(95 \% \mathrm{Cl})$ & $\mathrm{n} / \mathrm{N}$ & $\%(95 \% \mathrm{Cl})$ \\
\hline \multicolumn{7}{|l|}{ PACS in either eye } \\
\hline \multicolumn{7}{|l|}{ Age (years) } \\
\hline $50-59$ & $52 / 319$ & 16.3 (12.4 to 20.8 ) & $17 / 136$ & 12.5 (7.5 to 19.3$)$ & $35 / 183$ & 19.1 (13.7 to 25.6 ) \\
\hline $60-69$ & $36 / 186$ & 19.4 (13.9 to 25.8$)$ & $16 / 88$ & 18.2 (10.8 to 27.8$)$ & $20 / 98$ & 20.4 (12.9 to 29.8$)$ \\
\hline $70-79$ & $17 / 106$ & 16.0 (9.6 to 24.4$)$ & $4 / 50$ & 8.0 (2.2 to 19.2$)$ & $13 / 56$ & 23.2 (13.0 to 36.4) \\
\hline $80+$ & $0 / 9$ & 0 & $0 / 3$ & 0 & $0 / 6$ & 0 \\
\hline Total & $105 / 620$ & 16.9 (14.1 to 20.1$)$ & $37 / 277$ & 13.4 (9.6 to 17.9$)$ & $68 / 343$ & 19.8 (15.7 to 24.4$)$ \\
\hline \multicolumn{7}{|l|}{ PAC/G in either eye } \\
\hline \multicolumn{7}{|l|}{ Age (years) } \\
\hline $50-59$ & $7 / 319$ & 2.2 (0.9 to 4.5$)$ & $3 / 136$ & $2.2(0.5$ to 6.3$)$ & $4 / 183$ & 2.2 (0.6 to 5.5$)$ \\
\hline $60-69$ & $9 / 186$ & $4.8(2.2$ to 9.0$)$ & $2 / 88$ & $2.3(0.3$ to 8.0$)$ & $7 / 98$ & 7.1 (2.9 to 14.2 ) \\
\hline $70-79$ & $5 / 106$ & 4.7 (1.5 to 10.7$)$ & $2 / 50$ & $4.0(0.5$ to 13.7$)$ & $3 / 56$ & 5.4 (1.1 to 14.9$)$ \\
\hline $80+$ & $1 / 9$ & 11.1 (0.3 to 48.2$)$ & $0 / 3$ & 0 & $1 / 6$ & $16.7(0.4$ to 64.1$)$ \\
\hline Total & $22 / 620$ & $3.6(2.2$ to 5.3$)$ & $7 / 277$ & 2.5 (1.0 to 5.1$)$ & $15 / 343$ & $4.4(2.5$ to 7.1$)$ \\
\hline \multicolumn{7}{|c|}{ Any PAC disease in either eye } \\
\hline \multicolumn{7}{|l|}{ Age (years) } \\
\hline $50-59$ & $59 / 319$ & 18.5 (14.4 to 23.2$)$ & $20 / 136$ & 14.7 (9.2 to 21.8$)$ & $39 / 183$ & 21.3 (15.6 to 28.0$)$ \\
\hline $60-69$ & $45 / 186$ & 24.2 (18.2 to 31.0$)$ & $18 / 88$ & 20.5 (12.6 to 30.4$)$ & $27 / 98$ & 27.6 (19.0 to 37.5$)$ \\
\hline $70-79$ & $22 / 106$ & 20.8 (13.5 to 29.7) & $6 / 50$ & $12.0(4.5$ to 24.3$)$ & $16 / 56$ & 28.6 (17.3 to 42.2$)$ \\
\hline $80+$ & $1 / 9$ & 11.1 (0.3 to 48.2$)$ & $0 / 3$ & 0 & $1 / 6$ & 16.7 (0 to 64.1$)$ \\
\hline Total & $127 / 620$ & 20.5 (17.4 to 24.9$)$ & $44 / 277$ & 15.9 (11.8 to 20.7$)$ & $83 / 343$ & 24.2 (19.8 to 29.1$)$ \\
\hline
\end{tabular}

PAC, primary angle closure; PAC/G, primary angle closure/glaucoma; PACS, primary angle closure suspects.

$5.3 \%)$ at baseline, those who had undergone bilateral cataract surgery during the follow-up period $(47,27.5 \%)$, and those with missing data on gonioscopy $(46,26.9 \%)$.

The overall 10-year incidence of any form of PAC was $20.5 \%$ (127/620, 95\% CI $17.4 \%$ to $24.9 \%)$. PAC incidence did not increase with age overall, but women aged 70-79 years had a higher incidence $(28.6 \%, 95 \%$ CI $17.3 \%$ to $42.2 \%)$ than those aged $50-59$ years $(21.3 \%, 95 \%$ CI $15.6 \%$ to $28.0 \%)$ (table 1 ).

PACS was the most common form of angle closure to develop, with 105 of 127 incident cases (82.7\%) being classified as PACS. The 10-year incidence of PACS was 16.9\% (95\% CI $14.1 \%$ to $20.1 \%$ ) and incident PACS increased with age among women, from $19.1 \%$ (95\% CI $13.7 \%$ to $25.6 \%$ ) in those aged 50-59 years old to $23.2 \%$ (95\% CI $13.0 \%$ to $36.4 \%$ ) in those aged 70-79 years old, although this was not statistically significant. Women overall were more likely to develop incident angle closure than men $(19.8 \%$ vs $13.4 \%, p=0.03)$. Twenty-two of the 127 incident cases who developed incident PAC/G included 15 cases of PAC and 7 cases of PACG in either eye. Therefore, the incidence of PAC was $2.4 \%$ (95\% CI $1.4 \%$ to $4.0 \%$ ), and the incidence of PACG was $1.1 \%$ (95\% CI $0.5 \%$ to $2.3 \%$ ). Among the 15 eyes with PAC, 3 were presented with an elevated IOP, 11 had PAS, and 1 had both an elevated IOP and PAS (table 1).

Compared with those who did not develop any form of angle closure over the 10-year period, incident cases were more likely to be female $(\mathrm{p}=0.01)$, had narrower angle width $(2.56 \pm 1.01$ vs $3.33 \pm 0.90, \mathrm{p}<0.001)$, had thicker lenses $(4.48 \pm 0.63 \mathrm{~mm}$ vs $4.13 \pm 0.63 \mathrm{~mm}, \mathrm{p}<0.001)$, had shorter AL $(22.7 \pm 0.82 \mathrm{~mm}$ vs $23.5 \pm 1.37 \mathrm{~mm}, \mathrm{p}<0.001)$, had shallower ACD $(2.57 \pm 0.28$ $\mathrm{mm}$ vs $2.80 \pm 0.33 \mathrm{~mm}, \mathrm{p}<0.001)$ and had a more hyperopic SE $(0.58 \mathrm{D}$ vs $-0.59 \mathrm{D}, \mathrm{p}<0.001)$ at baseline (table 2$)$. Figure 2 presents the relationship between 10-year incidences of angle closure and AL, ACD and LT. The incidence increased dramatically in eyes shorter than $22 \mathrm{~mm}$ in AL and in those with ACD less than $2.5 \mathrm{~mm}$ and LT of more than $5.0 \mathrm{~mm}$.
In multivariate logistic regression, significant risk factors for incidence of any form of PAC were thicker LT $(\mathrm{OR}=1.82$ per $\mathrm{mm}, 95 \%$ CI 1.24 to $2.69, \mathrm{p}=0.003)$, shallower $\mathrm{ACD}(\mathrm{OR}=3.18$ per $\mathrm{mm}$ decrease, $95 \%$ CI 1.32 to $7.70, \mathrm{p}=0.010)$ and narrower angle width $(\mathrm{OR}=1.63$ per decreased angle width grade, $95 \% \mathrm{CI}$ 1.26 to $2.11, \mathrm{p}<0.001$ ), and shorter AL was marginally associated with incidence of any form of PAC $(\mathrm{OR}=1.29$ per dioptre, 95\% CI 0.98 to $1.70, \mathrm{p}=0.071$; table 2).

We used ROC analysis to assess the potential performance of ACD, LT and AL as determinants of incident PACS, PAC/G and any angle closure. The AUC was 0.728 (95\% CI 0.674 to 0.783$), 0.686$ (95\% CI 0.621 to 0.749 ) and 0.687 (95\% CI 0.632 to 0.742 ), with best cut-off values of 2.60, 4.72 and $22.92 \mathrm{~mm}$, for ACD, LT and AL, respectively, in predicting incident PAC spectrum. The sensitivity and specificity were $74.1 \%$ and $57.1 \%$ for ACD with best cut-off values, while the corresponding figures were $46.3 \%$ and $82.6 \%$ for LT, and $65.4 \%$ and $60.9 \%$ for AL (table 3 and online supplementary figure 1).

\section{DISCUSSION}

The cumulative incidence of any form of PAC over the 10-year period in this population-based sample of Chinese individuals was high (20.5\%), but most of the angle closures were mild and did not result in elevated IOP or PAS. This is the first population-based study evaluating the incidence of PAC among elderly Chinese individuals, a high-risk population for angle closure. As in previous cross-sectional studies, ${ }^{9}{ }^{10}$ greater LT, shallower ACD, narrower angle width and more hyperopic SE at baseline were predictors for the development of angle closure.

Available data on the incidence of various forms of PAC are summarised in online supplementary table 2 . We found a substantially higher incidence of angle closure $(2.05 \%$ annually) than was reported in an Indian population aged 40 years 
Table 2 Factors associated with 10-year incidence of any forms of primary angle closure in the Liwan Eye Study

\begin{tabular}{|c|c|c|c|c|c|c|}
\hline \multirow[b]{2}{*}{ Baseline characteristics } & \multirow{2}{*}{$\begin{array}{l}\text { Participants who } \\
\text { developed incident } \\
\text { primary angle closure } \\
\text { disease } \\
\mathrm{n}(\%)\end{array}$} & \multirow{2}{*}{$\begin{array}{c}\text { Participants who did } \\
\text { not develop incident } \\
\text { primary angle closure } \\
\text { disease } \\
n(\%)\end{array}$} & \multicolumn{2}{|c|}{$\begin{array}{c}\text { Univariate } \\
\text { logistic regression }\end{array}$} & \multicolumn{2}{|c|}{$\begin{array}{l}\text { Multivariate } \\
\text { logistic regression }\end{array}$} \\
\hline & & & OR $(95 \% \mathrm{Cl})$ & $P$ values & OR $(95 \% \mathrm{Cl})$ & $P$ values \\
\hline Number of participants & $127(20.5)$ & $493(79.5)$ & & & & \\
\hline Age (years) & $61.1 \pm 7.72$ & $60.8 \pm 8.48$ & 1.0 (0.98 to 1.03$)$ & 0.753 & $0.97(0.95$ to 1.00$)$ & 0.079 \\
\hline Female & $83(65.4)$ & $260(52.7)$ & 1.69 (1.13 to 2.54$)$ & 0.011 & 1.15 (0.71 to 1.84$)$ & 0.580 \\
\hline Education, none & $24(19.1)$ & $70(14.7)$ & 1.37 (0.82 to 2.29$)$ & 0.227 & & \\
\hline Low income, $<¥ 1000 /$ month & $72(75.8)$ & $244(69.1)$ & 1.40 (0.83 to 2.35 ) & 0.207 & & \\
\hline Diabetes, present & $8(6.4)$ & $40(8.3)$ & 0.75 (0.34 to 1.64$)$ & 0.464 & & \\
\hline Hypertension, present & $52(41.6)$ & $195(40.5)$ & 1.04 (0.70 to 1.56$)$ & 0.830 & & \\
\hline $\mathrm{BMI}\left(\mathrm{kg} / \mathrm{m}^{2}\right)$ & $23.4 \pm 3.30$ & $23.6 \pm 3.03$ & $0.98(0.91$ to 1.05$)$ & 0.510 & & \\
\hline Mean angle width & $2.56 \pm 1.01$ & $3.33 \pm 0.90$ & 2.15 (1.75 to 2.63 ) & $<0.0001$ & 1.63 (1.26 to 2.11$)$ & $<0.0001$ \\
\hline $\mathrm{AL}(\mathrm{mm})$ & $22.7 \pm 0.82$ & $23.5 \pm 1.37$ & 2.09 (1.63 to 2.69$)$ & $<0.0001$ & $1.29(0.98$ to 1.70$)$ & 0.071 \\
\hline $\mathrm{ACD}(\mathrm{mm})$ & $2.57 \pm 0.28$ & $2.80 \pm 0.33$ & $13.0(6.13$ to 27.6$)$ & $<0.0001$ & $3.18(1.32$ to 7.70$)$ & 0.010 \\
\hline LT (mm) & $4.48 \pm 0.63$ & $4.13 \pm 0.63$ & 2.93 (2.05 to 4.19$)$ & $<0.0001$ & 1.82 (1.24 to 2.69$)$ & 0.003 \\
\hline Absolute lens position & $4.80 \pm 0.35$ & $4.86 \pm 0.44$ & 0.84 (0.52 to 1.36$)$ & 0.478 & & \\
\hline Relative lens position & $2.11 \pm 0.15$ & $2.07 \pm 0.18$ & 6.32 (1.94 to 20.7) & 0.002 & & \\
\hline SE (D) & $0.58 \pm 1.28$ & $-0.59 \pm 2.82$ & 1.31 (1.14 to 1.49$)$ & $<0.0001$ & & \\
\hline IOP (mm Hg) & $15.1 \pm 3.06$ & $15.4 \pm 3.06$ & 0.96 (0.90 to 1.02$)$ & 0.216 & & \\
\hline $\mathrm{CCT}(\mu \mathrm{m})$ & $544 \pm 31.5$ & $541 \pm 33.5$ & 1.00 (0.99 to 1.01$)$ & 0.434 & & \\
\hline
\end{tabular}

$\mathrm{ACD}$, anterior chamber depth; AL, axial length; BMI, body mass index; $\mathrm{CCT}$, central cornea thickness; IOP, intraocular pressure; $\mathrm{LT}$, lens thickness; $\mathrm{SE}$, spherical equivalences.

and older $\left(0.7 \%\right.$ annually). ${ }^{4}$ In a study of a high-risk Mongolian population aged 50 years or older with ACD $<2.53 \mathrm{~mm}$, the 6-year incidence of PACS was $20.4 \% .^{6}$ If we look only at this group of individuals, with similar cut-off in the present study, the incidence was $25.6 \%$ (2.56\% annually), which was lower than what was found in the Mongolian population. A 10-year follow-up study of Greenland Inuit persons with ACD $\leq 2.70$ $\mathrm{mm}$ or limbal ACD $<1 / 4$ of cornea thickness (CT) at baseline showed $16 \%$ developed angle closure, ${ }^{5}$ less than what was found in our study. The consistently high incidence in Inuit, Mongolian and Chinese populations ${ }^{11} 12$ supported the theory that people with East Asian background have higher risk of angle closure.

We further observed that the incidence was higher in women. A higher incidence of PAC among women has been consistently found in previous research, including the Mongolian ${ }^{6}$ and Inuit ${ }^{5}$ studies noted above. Such a difference was not seen in the study from India, but most population-based studies have found that women have nearly threefold higher prevalence of angle closure. ${ }^{4}$

Cross-sectional studies consistently suggest that older people have a higher prevalence of angle closure, but this could be attributable to either a genuine ageing effect or cohort effects. A cohort effect is suggested if a group of people's life experience influences the outcome of interest; for example, a more recently born cohort of people may have been exposed to better education, leading to higher rates of myopia, which might result in deeper ACD and lower rates of angle closure. The incidence data observed in the current study found a higher incidence of angle closure in older people, and therefore appear to suggest the increased prevalence of PAC in older people may largely be attributable to ageing effects. This conclusion seems to be further supported by another of our studies where we observed significant reduction on ACD in a 2-year follow-up of older Chinese. ${ }^{13}$ Interestingly, the Chennai Eye Study reported that the incidence of any form of PAC decreases with age, but this may partly be explained by a much higher number of cataract surgeries being performed in the Indian population. One study using data from Myanmar ${ }^{14}$ estimated that if cataract surgery were performed on $8.8 \%$ of eyes with visually significant cataract, it would reduce the incidence of angle closure in the adult population by $38.5 \%$. Therefore it is likely that our study underestimates the true incidence of angle closure since our study subjects were engaged with the eye care system and many received cataract surgery.

The important risk factors for incident angle closure, shallower ACD, thicker LT and narrower angle width have consistently been shown to be associated with angle closure in previous cross-sectional and longitudinal studies. ${ }^{491516}$ Therefore, these biometric factors are often used as indicators for screening to identify the people at risk on developing PAC and PACG, although most of these analyses are based on cross-sectional data. Our study is perhaps the first longitudinal study assessing the efficacy of these parameters in 'predicting' the onset of any forms of PAC in the future. Most of the cross-sectional studies reported a much better performance using ACD as a screening tool, with an AUC of 0.85 or greater, ${ }^{17-20}$ which is much higher than what we observed in this longitudinal study. None of these parameters have strong enough predictive ability to warrant their use in determining who requires more intensive monitoring.

The strength of this study lies in the population-based cohort design with standardised protocols and data collected by trained researchers. In addition, gonioscopy examinations were performed by a single, experienced ophthalmologist to ensure the consistency of results. The main limitation of this study is loss to follow-up, although our data suggest that the participants and non-participants did not differ in terms of ocular parameters. Another limitation of this study is the lack of successful completion of gonioscopy among participants in the older age groups who were unable to cooperate with gonioscopy. As the rate of angle closure is expected to be higher in older people, this may perhaps result in an underestimation in the overall 

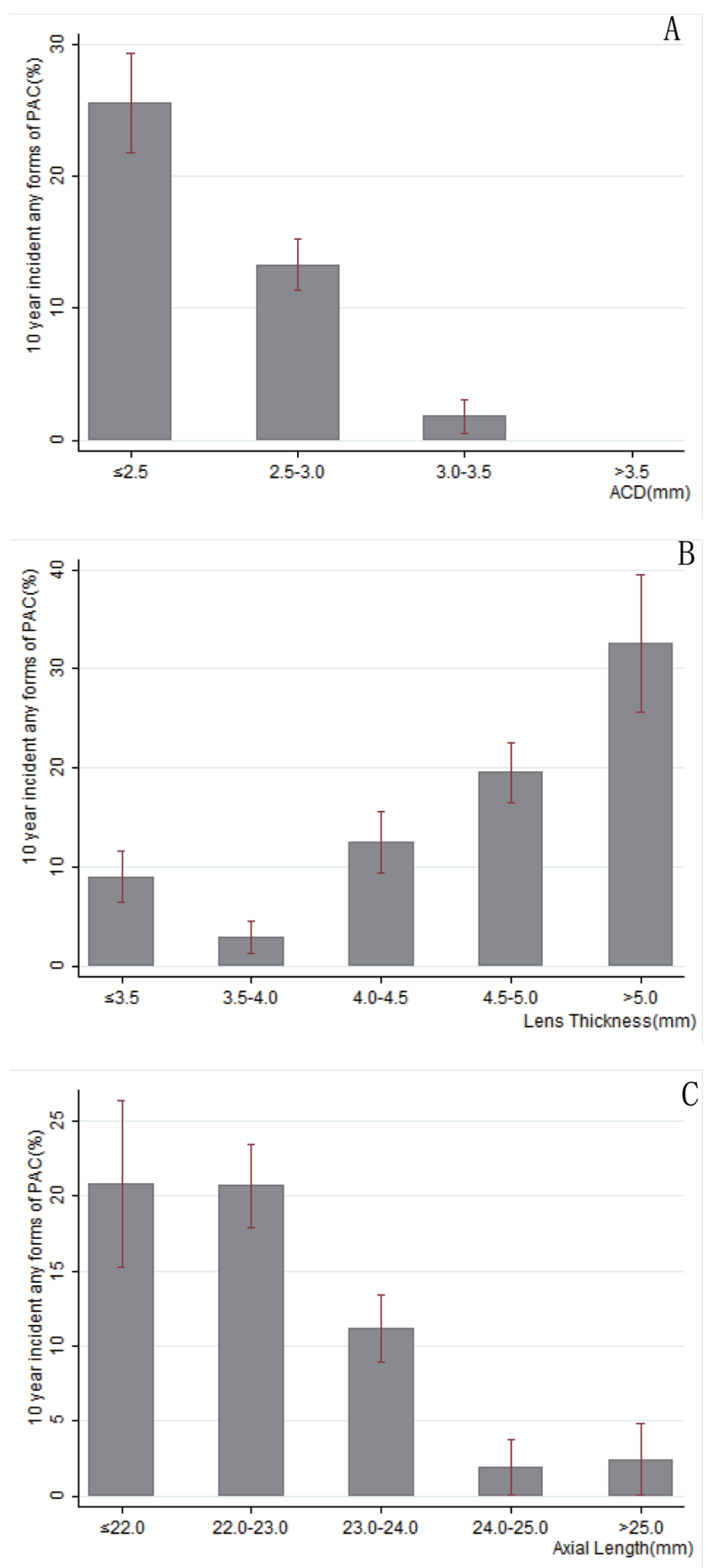

Figure 2 Ten-year incidence of any forms of primary angle closure (PAC) and association with axial length, anterior chamber depth and lens thickness in the right eyes in the Liwan Eye Study: (A) association with anterior chamber depth (ACD); (B) association with lens thickness; and $(C)$ association with axial length.

incidence. In addition, the number of observation in very old cohort (80 years and older) is small, with insufficient power to estimate the incidence. However, all these problems should not have affected the age-specific rates unless those who could not undergo gonioscopy were likely to have angle closure. One should also note that during the 10-year follow-up, 47 people who had received cataract surgery were removed from the analysis, possibly biasing the estimation on incidence rate.
Table 3 Area under the curve, best cut-off and ORs of ocular parameters at baseline for 10-year incident primary angle closure

\begin{tabular}{|c|c|c|c|c|}
\hline $\begin{array}{l}\text { Ocular biometry } \\
\text { at baseline }\end{array}$ & $\begin{array}{l}\text { Best } \\
\text { cut-off }\end{array}$ & $\begin{array}{l}\text { Area under the curve } \\
(95 \% \mathrm{Cl})\end{array}$ & $\begin{array}{l}\text { Sensitivity } \\
(\%)\end{array}$ & $\begin{array}{l}\text { Specificity } \\
(\%)\end{array}$ \\
\hline \multicolumn{5}{|l|}{ PACS } \\
\hline $\mathrm{ACD}(\mathrm{mm})$ & 2.59 & $0.725(0.665$ to 0.785$)$ & 74.3 & 58.3 \\
\hline LT (mm) & 4.72 & 0.672 (0.596 to 0.747$)$ & 44.7 & 80.6 \\
\hline $\mathrm{AL}(\mathrm{mm})$ & 22.92 & $0.663(0.601$ to 0.726$)$ & 64.0 & 59.7 \\
\hline \multicolumn{5}{|l|}{ PAC/G } \\
\hline $\mathrm{ACD}(\mathrm{mm})$ & 2.70 & 0.674 (0.561 to 0.786$)$ & 57.7 & 70.0 \\
\hline LT (mm) & 4.37 & 0.678 (0.582 to 0.775$)$ & 53.7 & 90.0 \\
\hline $\mathrm{AL}(\mathrm{mm})$ & 22.87 & 0.711 (0.609 to 0.813$)$ & 65.2 & 65.0 \\
\hline \multicolumn{5}{|l|}{ Any PAC disease } \\
\hline $\mathrm{ACD}(\mathrm{mm})$ & 2.60 & 0.728 (0.674 to 0.783$)$ & 74.1 & 57.1 \\
\hline LT (mm) & 4.72 & $0.686(0.621$ to 0.749$)$ & 46.3 & 82.6 \\
\hline $\mathrm{AL}(\mathrm{mm})$ & 22.92 & 0.687 (0.632 to 0.742$)$ & 65.4 & 60.9 \\
\hline
\end{tabular}

$A C D$, anterior chamber depth; $A L$, axial length; $L T$, lens thickness; $P A C$, primary angle closure; PAC/G, primary angle closure/glaucoma; PACS, primary angle closure suspect.

In conclusion, this study is the first to report the 10-year incidence of any forms of PAC in a population-based sample of the elderly Chinese. The study confirmed the incidence of PAC increasing with age, and also confirmed that the biometric anatomical parameters including shallower ACD, thicker LT, narrower angle width and more hyperopic SE are independent predictive factors for the development of angle closure. While the incidence of any form of PAC was high (over 20\%), the overwhelming majority was angle crowding with no clear adverse effect on the health of the eye. Teasing apart who will and will not develop angle closure and high eye pressure or glaucoma will require even larger cohorts to be followed.

Contributors Conception and design of the study: MH, DSF, PJF; analysis and interpretation: LW, WH, JZ; writing of the article: LW, XG; critical revision of the article: MH, DSF, PJF; data collection: LW, WH, SH.

Funding This study was supported by the Fundamental Research Funds of the State Key Laboratory in Ophthalmology, National Natural Science Foundation of China (81420108008 and 81570843 H1204), and the Science and Technology Planning Project of Guangdong Province, China (2013B20400003). The sponsor or funding organisation had no role in the design or conduct of this research. $\mathrm{MH}$ receives support from the University of Melbourne at Research Accelerator Program and the CERA Foundation. The Centre for Eye Research Australia receives Operational Infrastructure Support from the Victorian State Government. PJF receives research funding from the NIHR Biomedical Research Centre at Moorfields Eye Hospital and UCL Institute of Ophthalmology.

Competing interests None declared.

Patient consent Obtained.

Ethics approval Ethical approval was obtained from the Zhongshan University Ethics Review Board and the Research Governance Committee of Moorfields Eye Hospital in London, England.

Provenance and peer review Not commissioned; externally peer reviewed.

(C) Author(s) (or their employer(s)) 2019. No commercial re-use. See rights and permissions. Published by BMJ.

\section{REFERENCES}

1 Quigley HA, Broman AT. The number of people with glaucoma worldwide in 2010 and 2020. Br J Ophthalmol 2006;90:262-7.

2 Foster PJ, Buhrmann R, Quigley HA, et al. The definition and classification of glaucoma in prevalence surveys. Br J Ophthalmol 2002;86:238-42.

3 He M, Foster PJ, Johnson GJ, et al. Angle-closure glaucoma in East Asian and European people. Different diseases? Eye 2006;20:3-12.

4 Vijaya L, Asokan R, Panday M, et al. Six-year incidence of angle-closure disease in a South Indian population: the Chennai Eye Disease Incidence Study. Am I Ophthalmol 2013;156:1308-15. 
5 Alsbirk PH. Anatomical risk factors in primary angle-closure glaucoma. A ten year follow up survey based on limbal and axial anterior chamber depths in a high risk population. Int Ophthalmol 1992;16(4-5):265-72.

6 Yip JL, Foster PJ, Gilbert CE, et al. Incidence of occludable angles in a high-risk Mongolian population. Br J Ophthalmol 2008;92:30-3.

7 He M, Foster PJ, Ge J, et al. Prevalence and clinical characteristics of glaucoma in adult Chinese: a population-based study in Liwan District, Guangzhou. Invest Ophthalmol Vis Sci 2006;47:2782-8.

8 Shaffer RN. Operating room gonioscopy in angle-closure glaucoma surgery. AMA Arch Ophthalmol 1958;59:532-5.

9 George R, Paul PG, Baskaran M, et al. Ocular biometry in occludable angles and angle closure glaucoma: a population based survey. Br J Ophthalmol 2003;87:399-402.

10 Lavanya R, Wong TY, Friedman DS, et al. Determinants of angle closure in older Singaporeans. Arch Ophthalmol 2008;126:686-91.

11 Ye T, Yu Q, Peng S, et al. [Six year follow-up of suspects of primary angle-closure glaucoma]. Zhonghua Yan Ke Za Zhi 1998;34:167-9.

12 Baskaran M, lyer JV, Narayanaswamy AK, et al. Anterior segment imaging predicts incident gonioscopic angle closure. Ophthalmology 2015;122:2380-4.

13 Congdon NG, Kong X, Meltzer ME, et al. Determinants and two-year change in anterior chamber angle width in a Chinese population. Ophthalmology 2012;119:2500-6.
14 Chan W, García JA, Newland HS, et al. Killing two birds with one stone: the potential effect of cataract surgery on the incidence of primary angle-closure glaucoma in a high-risk population. Clin Exp Ophthalmol 2012;40:e128-34.

15 Kashiwagi K, Chiba T, Mabuchi F, et al. Five-year incidence of angle closure among glaucoma health examination participants. Graefes Arch Clin Exp Ophthalmol 2013;251:1219-28.

16 Casson RJ, Baker M, Edussuriya K, et al. Prevalence and determinants of angle closure in central Sri Lanka: the Kandy Eye Study. Ophthalmology 2009:116:1444-9.

17 Nolan WP, Aung T, Machin D, et al. Detection of narrow angles and established angle closure in Chinese residents of Singapore: potential screening tests. Am J Ophthalmol 2006;141:896-901.

18 Wang B, Nongpiur ME, Liu J, et al. Analysis of association between the insertion location of Iris root and narrow angle. J Glaucoma 2015;24:433-7.

19 Devereux JG, Foster PJ, Baasanhu J, et al. Anterior chamber depth measurement as a screening tool for primary angle-closure glaucoma in an East Asian population. Arch Ophthalmol 2000;118:257-63.

20 Zhang Y, Li SZ, Li L, et al. The Handan Eye Study: comparison of screening methods for primary angle closure suspects in a rural Chinese population. Ophthalmic Epidemiol 2014:21:268-75 